Ida Adha Anrosana P, Ariesia Ayuning Gemaputri. Kajian Daya Dukung (Carrying Capacity) Lingkungan Perairan Pantai Pasir Putih Situbondo bagi Pengembangan Usaha Karamba Jaring Apung.

\title{
Kajian Daya Dukung (Carrying Capacity) Lingkungan Perairan Pantai Pasir Putih Situbondo bagi Pengembangan Usaha Karamba Jaring Apung
}

\section{Carrying Capacity Standards Environmental of Pasir Putih Coastal Situbondo For Business Development Of Karamba Floating Net}

\author{
Ida Adha Anrosana $P^{\# 1}$, Ariesia Ayuning Gemaputri ${ }^{\#}$ \\ Program Studi Manajemen Agribisnis Jurusan Manajemen Agribisnis Politeknik Negeri Jember \\ Jalan Mastrip Kotak Pos 164 Jember \\ idapongoh@ymail.com
}

\begin{abstract}
Sustainable sea cultivation has efficient features in resource use, productive and non-destructive environments. Under the Code of Conduct of Responsible Fisheries governing sustainable aquaculture development, it emphasizes the importance of a preliminary evaluation of the impact of aquaculture on genetic diversity, the integrity of the ecosystem, and the life of local communities (Sudrajat, 2008). This study was conducted with the main purpose of obtaining accurate information about the carrying capacity of the aquatic environment used for the development of floating net karamba business in the Pasir Putih Beach area of Situbondo Regency.

Based on the results of research that has been done in Karamba Floating Net Pasir Putih Coastal Situbondo, it can be concluded that (1) The water quality in the aquatic environment in KJA area of Pasir Putih Beach Situbondo is still in accordance with the sea water quality standard of KepMen LH No. 51 of 2004 and considered feasible for the development of aquaculture activities in Karamba Floating Net.
\end{abstract}

Keywords : Carrying Capacity, Karamba Floating Net

\section{PENDAHULUAN}

Daya dukung lingkungan atau carrying capacity mengandung pengertian kemampuan suatu tempat dalam menunjang kehidupan mahluk hidup secara optimum dalam periode waktu yang panjang. Daya dukung lingkungan dapat pula diartikan kemampuan lingkungan memberikan kehidupan organisme secara sejahtera dan lestari bagi penduduk yang mendiami suatu kawasan. Kemampuan lingkungan untuk mendukung perikehidupan semua makhluk hidup yang meliputi ketersediaan sumber daya alam untuk memenuhi kebutuhan dasar dan tersedianya cukup ruang untuk hidup pada tingkat kestabilan sosial tertentu disebut daya dukung lingkungan (Undang-undang No. 23 Tahun 1997 Tentang Pengelolaan Lingkungan Hidup). Informasi mengenai daya dukung lingkungan (carrying capacity) pada suatu kawasan perairan sangat berperan pada pengelolaan dan pengembangan kegiatan budidaya perikanan. Penelitian ini bertujuan untuk mendapatkan informasi daya dukung lingkungan perairan pantai Situbondo sebagai kawasan pengembangan budidaya perikanan di pesisir utara pulau Jawa 
Kegiatan pembesaran ikan di karamba jaring apung (KJA) memberikan imbas positif dan negatif. Imbas positif dari kegiatan budidaya di karamba jaring apung adalah peningkatan produksi dari sektor perikanan dan dapat meningkatkan tingkat sosial masyarakat yang tinggal di sekitar waduk. Namun selain itu dampak negatif dari kegiatan ini adalah dampak pencemaran lingkungan sehingga mengakibatkan menurunnya kualitas perairan yang disebabkan oleh sisa pakan yang tidak terkonsumsi oleh ikan dan hasil dari kegiatan metabolism ikan (feses dan urin) sehingga terjadinya pendangkalan (sedimentasi) permukaan (BPWC, 2005). Persyaratan teknis yang harus diperhatikan dalam memilih lokasi usaha budidaya ikan di karamba jaring apung antara lain arus air, tingkat kesuburan, bebas dari pencemaran kualitas air, dan konstruksi bangunan (Direktorat Pembudidayaan, Ditjen Perikanan Budidaya, DKP, 2002).

Penelitian tentang daya dukung lingkungan perairan untuk kegiatan budidaya ikan telah banyak dilakukan, seperti yang telah dilakukan oleh Suparjo (2008) yang berjudul "Daya Dukung Lingkungan Perairan Tambak Desa Mororejo Kabupaten Kendal". Hasil penelitian yang dilakukan dengan metode survey mengenai kualitas fisik, kimia, dan biologi perairan tambak ini memberikan gambaran bahwa perairan tambak di Desa Mororejo ini memiliki daya dukung sedang sampai tinggi dengan kandungan amoniak dan salinitas air sebagai pembatas.

Pada tahun 2011, Saputra melakukan penelitian dengan judul "Kajian Potensi Plankton Sebagai Ketersediaan Pakan Alami Untuk Ikan Air Tawar Di Karamba Jaring Apung Di Waduk Cirata Jawa Barat". Hasil penelitian ini menunjukkan bahwa plankton dari jenis fitoplankton sangat mendominasi dengan indeks rata-rata 77,9 \%. Plankton dapat digunakan sebagai salah satu parameter dalam pemantauan kualitas lingkungan perairan.

Penelitian lain yang dilakukan oleh Affan (2012) dengan judul "Identifikasi lokasi untuk pengembangan budidaya keramba jaring apung (KJA) berdasarkan faktor lingkungan dan kualitas air di perairan pantai timur Bangka Tengah", menunjukkan bahwa terdapat potensi lokasi seluas 127.746 ha, dimana 122.950 ha $(96,25 \%)$ diantaranya sangat layak sampai layak, dan 4.796 ha $(3,75 \%)$ cukup layak untuk peruntukan budidaya ikan.
Suatu perairan memiliki daya dukung yang berbeda-beda ditentukan oleh beberapa faktor yaitu fisika, kimia, biologi beserta interaksi didalamnya. Parameter fisika yang biasa digunakan untuk menentukan kualitas perairan meliputi cahaya, suhu, kecerahan dan kekeruhan, warna air, padatan total, padatan terlarut, padatan tersuspensi, dan salinitas (Effendi, 2003). Karakteristik kimia air sangat berpengaruh terhadap kehidupan aquatik. Karakteristik tersebut yaitu $\mathrm{pH}$, salinitas, $\mathrm{CO}_{2}$ dan $\mathrm{O}_{2}$ terlarut, serta kandungan material beracun termasuk bahan organik seperti amoniak, nitrit, logam berat maupun kimia sintetis (Lesmana 2001). Kualitas air secara biologik, khususnya secara mikrobiologik ditentukan oleh parameter mikrobia pencemar, patogen dan penghasil toksin. Banyak jenis bakteri patogen dan toksin berkembang dan menyebar melalui badan air, baik yang hidup secara anaerobik maupun yang hidup secara aerobik (Suriawiria 1996).

Informasi mengenai daya dukung lingkungan (carrying capacity) pada suatu kawasan perairan sangat berperan pada pengelolaan dan pengembangan kegiatan budidaya perikanan. Penelitian ini bertujuan untuk mendapatkan informasi daya dukung lingkungan perairan pantai Situbondo sebagai kawasan pengembangan budidaya perikanan di pesisir utara pulau Jawa.

\section{METODOLOGI}

\section{Waktu dan Lokasi Penelitian}

Pengumpulan data primer dilakukan di karamba jaring apung (KJA) yang terdapat pada pantai Pasir Putih Kabupaten Situbondo dan dilakukan selama 4 (empat) bulan mulai dari 13 April 2015 sampai dengan 16 Agustus 2015.

\section{Metode Penelitian}

Penelitian ini dilakukan dengan metode survey (survey research). Kegiatan ini dilaksanakan di perairan pantai Pasir Putih Situbondo. Data yang diambil berupa data primer yang diambil dengan 2 (dua) tahap utama, yaitu (1) Tahap 1, yaitu pengambilan data primer awal pagi hari sebelum diberi pakan di budidaya karamba jaring apung yang didasarkan dengan kegiatan survey di perairan Pantai Pasir Putih Situbondo, dan (2) Tahap 2, yaitu pengambilan data primer kualitas air siang hari sesudah diberi pakan pada kegiatan budidaya dikaramba jaring apung di perairan Pantai Pasir Putih Situbondo. 
Ida Adha Anrosana P, Ariesia Ayuning Gemaputri. Kajian Daya Dukung (Carrying Capacity) Lingkungan Perairan Pantai Pasir Putih Situbondo bagi Pengembangan Usaha Karamba Jaring Apung.

\section{Metode Pengumpulan Data}

\section{a. Cara Pengambilan Sampel Data}

Data kualitas perairan dikumpulkan berasal dari tiga titik stasiun yang mewakili lokasi pengamatan, untuk menganalisa secara spesifik, titik-titik tersebut terlebih dahulu dilakukan interpolasi. Metode penentuan stasiun pengambilan sampel menggunakan metode Inverse Distance Weight, (IDW). Pramono et al. (2005) dan Jhonson et al., (2001) menyebutkan bahwa metode IDW lebih cepat untuk mengiterpolasi data fisik wilayah pesisir karena tidak menghasilkan data melebihi data yang disampel. Metode ini megasumsikan tiap titik input mempunyai pengaruh yang bersifat lokal sehingga memberikan bobot yang besar pada sel yang terdekat dengan titik dibandingkan pada sel yang jauh dengan titik.

b. Metode Analisis Data

Metode pengumpulan dan analisis data terbagi menjadi 2 (dua) yaitu pengumpulan data oseanografi dan data kualitas air. Tahapan pengumpulan dan analisis data yang dilakukan adalah sebagai berikut :

1. Survei oseanografi

Tahap 1 : Menghitung luasan permukaan dari badan air (A-ha) dan ratarata kedalaman $(\mathrm{Z})$

Tahap $2 \quad$ : $\quad$ Mengukur steady state $[\mathrm{P}]_{\mathrm{i}}$ dari konsentrasi total-P yang ditentukan berdasarkan rataan tahunan konsentrasi total-P dalam badan air, data diperoleh dari sejumlah sampel $P$ $\left(\mathrm{mg} / \mathrm{m}^{3}\right)$ selama satu tahun

Tahap 3 : Menentukan [P] maksimum yang dapat diterima oleh badan air $[\mathrm{P}]_{\mathrm{f}}$ akibat adanya budidaya karamba jaring apung

Tahap 4 : Menentukan kapasitas badan air untuk budidaya karamba jaring apung secara intensif $\Lambda[\mathrm{P}]$, yaitu selisih antara $[\mathrm{P}]$ sebelum dimanfaatkan untuk budidaya $[\mathrm{P}]_{\mathrm{i}}$ dengan $[\mathrm{P}]$ maksimum yang dapat diterima setelah keberadaan karamba jaring apung $[\mathrm{P}]_{\mathrm{f}}$. Sehingga $\Lambda[\mathrm{P}]=[\mathrm{P}]_{\mathrm{f}}-[\mathrm{P}]_{\mathrm{i}}$

Tahap 5 : Menghitung jumlah ikan yang dapat diproduksi (ton/tahun)

Nilai kapasitas produksi ini akan digunakan sebagai petunjuk awal dalam menentukan daya dukung badan air untuk produksi ikan dalam karamba jaring apung.

2. Pengumpulan data kualitas air

a. Parameter kimia

\begin{tabular}{|c|c|c|}
\hline No. & Parameter & Spesifikasi Metode \\
\hline 1. & Salinitas & Refraktometerik \\
\hline 2. & $\begin{array}{l}\text { Phosphat } \\
\left(\mathrm{PO}_{4}\right)\end{array}$ & Refraktometerik \\
\hline 3. & $\begin{array}{l}\text { Bahan } \\
\text { organik } \\
\text { (TOM) }\end{array}$ & Titrimetrik \\
\hline 4. & Alkalinitas & Titrimetrik \\
\hline 5. & $\begin{array}{l}\text { Oksigen } \\
\text { terlarut / DO }\end{array}$ & Titrimetrik \\
\hline 6. & BOD & Titrimetrik \\
\hline 7. & Nitrit $\left(\mathrm{NO}_{2}\right)$ & $\begin{array}{c}\mathrm{IKM} / 5.4 .13 . \mathrm{K} / \mathrm{BBAP}- \\
\mathrm{S}\end{array}$ \\
\hline 8. & TAN & $\begin{array}{c}\mathrm{IKM} / 5.4 .14 . \mathrm{K} / \mathrm{BBAP}- \\
\mathrm{S}\end{array}$ \\
\hline 9. & $\begin{array}{l}\text { Amoniak } \\
\text { bebas }\end{array}$ & $\begin{array}{c}\mathrm{IKM} / 5.4 .14 . \mathrm{K} / \mathrm{BBAP}- \\
\mathrm{S}\end{array}$ \\
\hline 10. & $\mathrm{pH}$ & $\begin{array}{c}\mathrm{IKM} / 5.4 .15 . \mathrm{K} / \mathrm{BBAP}- \\
\mathrm{S}\end{array}$ \\
\hline
\end{tabular}

b. Parameter fisika

\begin{tabular}{ccc}
\hline No. & Parameter & $\begin{array}{c}\text { Spesifikasi } \\
\text { Metode }\end{array}$ \\
\hline 1. & Suhu air & Manual \\
& & (Termometer)
\end{tabular}

c. Parameter biologi

\begin{tabular}{clc}
\hline No. & \multicolumn{1}{c}{ Parameter } & Spesifikasi Metode \\
\hline 1. & Bakteri & Total Count \\
2. & Kemelimpahan & Direct Counting \\
& plankton & (Haemocytometer) \\
\hline
\end{tabular}

\section{HASIL DAN PEMBAHASAN \\ Hasil Penelitian}

Pengambilan data oseanografi dan kualitas air telah dilakukan selama 4 (empat) bulan mulai dari tanggal 13 April 2015 sampai dengan 16 Agustus 2015. Pengambilan data dilakukan di kawasan karamba jaring apung (KJA) yang terdapat di Pantai Pasir Putih Situbondo setiap satu minggu sekali dimana setiap pengambilan data dilakukan pagi dan sore hari. Hasil pengamatan dapat dilihat pada tabel 5.1 berikut : 
Jurnal Ilmiah INOVASI, Vol. 17 No. 2 Edisi Mei - Agustus 2017, ISSN 1411-5549

TABEL 5.1 HASIL PENGUKURAN KUALITAS AIR KARAMBA JARING APUNG DIPERAIRAN PANTAi PASIR PUTIH SITUBONDO

\begin{tabular}{|c|c|c|c|c|c|c|c|c|c|}
\hline \multirow{2}{*}{ NO } & \multirow{2}{*}{$\underline{\text { PARAMETER } P}$} & \multirow{2}{*}{$\frac{\text { SATUAN }}{\text { Unit }}$} & \multirow{2}{*}{$\frac{\text { Ambang }}{\underline{\text { Batas }}} \underset{\text { Standart }}{\text { Quality }}$} & \multicolumn{3}{|c|}{ PAGI } & \multicolumn{3}{|c|}{ SIANG } \\
\hline & & & & Sta. I & Sta. II & Sta. III & Sta. I & Sta. II & Sta. III \\
\hline 1 & $\mathrm{pH}$ & - & $6-9$ & 8,2 & 8,2 & 8,2 & 8,1 & 8,3 & 8,3 \\
\hline 2 & Salinitas & $\%$ & - & 35 & 35 & 35 & 35 & 35 & 35 \\
\hline 3 & Nitrit $\left(\mathrm{NO}_{2}\right)$ & $\mathrm{mg} / \mathrm{L}$ & 0,001 & 0,001 & 0,001 & 0,001 & 0,001 & 0,001 & 0,001 \\
\hline 4 & Amoniak bebas & $\mathrm{mg} / \mathrm{L}$ & 0,012 & 0,008 & 0,009 & 0,006 & 0,008 & 0,009 & 0,009 \\
\hline 5 & $\begin{array}{l}\text { Bahan } \\
\text { (TOM) }\end{array}$ & $\mathrm{mg} / \mathrm{L}$ & - & 98,908 & 103,332 & 99,224 & $\begin{array}{c}109,33 \\
6\end{array}$ & 103,016 & 109,968 \\
\hline 6 & Alkalinitas & $\mathrm{mg} / \mathrm{L}$ & - & 111 & 103 & 109,5 & 108 & 109 & 108 \\
\hline 7 & Phosphat & $\mathrm{mg} / \mathrm{L}$ & - & - & - & - & 0,308 & 0,297 & 0,289 \\
\hline 8 & Nitrat $\left(\mathrm{NO}_{3}\right)$ & $\mathrm{mg} / \mathrm{L}$ & $0,1^{2}$ & - & - & - & 5,8 & 5,7 & 9,3 \\
\hline 9 & DO & $\mathrm{mg} / \mathrm{L}$ & - & - & - & - & 5,11 & 4,37 & 4,47 \\
\hline 10 & BOD5 & $\mathrm{mg} / \mathrm{L}$ & - & - & - & - & 2,29 & 1,41 & 3,70 \\
\hline 11 & Suhu Permukaan & ${ }^{\circ} \mathrm{C}$ & - & 29 & 29 & 29 & 30,3 & 30,3 & 29,5 \\
\hline 12 & Suhu Kedalaman & ${ }^{\circ} \mathrm{C}$ & - & 27,8 & 27,8 & 27,8 & 29,8 & 29,0 & 29,0 \\
\hline 13 & Kedalaman KJA & $\mathrm{m}$ & - & 4,10 & 10,34 & 10,84 & 4,10 & 10,34 & 10,84 \\
\hline $\begin{array}{l}\text { Sumb } \\
\text { serta } \\
\text { perta } \\
\text { menja } \\
\text { ekosi }\end{array}$ & $\begin{array}{l}\text { r: Data Primer, } 2 \\
\text { Aktifitas peme } \\
\text { imbah domestik } \\
\text { an maupun da } \\
\text { li penyebab ut } \\
\text { em perairan yan }\end{array}$ & $\begin{array}{l}\text { haraan ik } \\
\text { ang beras } \\
\text { limbah } \\
\text { ma ment } \\
\text { berakhir }\end{array}$ & $\begin{array}{l}\text { dalam } \\
\text { dari keg } \\
\text { Imah ta } \\
\text { nnya fi } \\
\text { da terjad }\end{array}$ & & 7. & moditas ik & & $\mathrm{C}$ & $\begin{array}{l}4 \times 4 \mathrm{~m}^{2} \\
8 \times 4 \mathrm{~m}^{2} \\
\text { apu (Kerapu } \\
\text { an, Kerapu } \\
\text { ang, Kerapu } \\
\text { Cantik) }\end{array}$ \\
\hline
\end{tabular}
pencemaran perairan, mulai dari eutrofikasi yang menyebabkan ledakan (blooming) fitoplankton dan gulma air, upwelling dan lain-lain yang yang dapat mengakibatkan organisme perairan (terutama ikanikan budidaya) serta diakhiri dengan makin menebalnya lapisan anaerobik di badan air perairan. Hasil survey oseanografi dapat dilihat pada tabel 5.2 berikut

TABEL 5.2

HASIL SURVEY OSEANOGRAFI KAWASAN KARAMBA JARING APUNG DI PERAIRAN PANTAI PASIR PUTIH SITUBONDO

\begin{tabular}{clc}
\hline No. & Parameter Pengamatan & Hasil \\
\hline 1. & Luas Kawasan KJA & $24 \mathrm{Ha}$ \\
2. & $\begin{array}{l}\text { Kedalaman kolom air } \\
\text { bawah karamba }\end{array}$ & $7-14 \mathrm{~m}$ \\
3. & Kecerahan air & \\
4. & Kecepatan arus & $40 \mathrm{~cm}$ \\
5. & Jumlah KJA yang & $45 \mathrm{~cm} /$ detik \\
& beroperasi
\end{tabular}

6. Luas petakan KJA yang a. $3 \times 3 \mathrm{~m}^{2}$
Sumber: Data primer, 2015

Plankton adalah suatu organisme yang berukuran kecil dan jumlahnya sangat banyak, hidup melayang atau sedikit bergerak dan terombangambing oleh arus di perairan bebas. Plankton terdapat dalam dua bentuk yaitu fitoplankton dan zooplankton (Hutabarat 2000). Fitoplankton adalah organisme renik yang dapat berfotosintesis karena mengandung klorofil dan berperan sebagai penghasil $\mathrm{O} 2$ dan juga sebagai makanan bagi zooplankton. Dalam jumlah yang tepat fitoplankton berperan penting dalam produktivitas primer perairan. Wardoyo (1982) mengatakan bahwa kesuburan perairan ditentukan oleh kemampuan perairan tersebut untuk menghasilkan bahan organik dari bahan anorganik. Salah satu cara untuk mengetahuinya adalah dengan mengukur kelimpahan fitoplankton. 
Ida Adha Anrosana P, Ariesia Ayuning Gemaputri. Kajian Daya Dukung (Carrying Capacity) Lingkungan Perairan Pantai Pasir Putih Situbondo bagi Pengembangan Usaha Karamba Jaring Apung.

TABEL 5.3

KEMELIMPAHAN DAN KEANEKARAGAMAN PLANKTON DI Karamba Jaring APUNG PANTAI PASIR PUTIH Situbondo

\begin{tabular}{|c|c|c|}
\hline \multicolumn{3}{|c|}{ Kemelimpahan } \\
\hline Stasiun & $\begin{array}{c}\text { Plankton } \\
\left(\mathrm{sel} / \mathrm{m}^{3}\right)\end{array}$ & Jenis Plankton \\
\hline 1 & 118.800 & $\begin{array}{l}\text { Pleurosygma sp, Navicula } \\
\mathrm{sp}, \text { Branchionus sp, Limbya } \\
\mathrm{sp}, \text { Coscinodiscus } \mathrm{sp}, \\
\text { Copepoda, Diatome, } \\
\text { Anabena }\end{array}$ \\
\hline 2 & 118.800 & $\begin{array}{l}\text { Pleurosygma } \mathrm{sp}, \\
\text { Ocylatoria, Melasyra, } \\
\text { Limbya, Branchionus, } \\
\text { Sceletonema costatum, } \\
\text { Coscinodiscus } \mathrm{sp}\end{array}$ \\
\hline 3 & 221.400 & $\begin{array}{l}\text { Navicula sp, Amphora, } \\
\text { Pleurosigma, Ocyloteria, } \\
\text { Limbya, } \\
\text { Branchionus, Thalassiothrix } \\
\text { nitzschiodes, Chaetoceros } \\
\text { decipiens, Eucamphia } \mathrm{sp}, \\
\text { Peridinium clavus ABE }\end{array}$ \\
\hline
\end{tabular}

Sumber: Data Primer, 2015

\section{Pembahasan}

Budidaya ikan dengan Karamba Jaring Apung (KJA) di kawasan perairan Pantai Pasir putih Situbondo merupakan budidaya berbasis pelet (budidaya intensif), dengan kata lain kegiatan usaha yang efisien secara mikro tetapi inefisien secara makro, terutama apabila ditinjau dari segi dampaknya terhadap lingkungan. Pertumbuhan jumlah keramba yang terus meningkat yang berarti terus meningkatnya jumlah ikan yang dipelihara akan menghasilkan sejumlah limbah organik yang besar akibat pemberian pakan yang tidak efektif dan efisien.

Pengamatan dilakukan pada 3 (tiga) stasiun, dimana stasiun 1 terletak pada 7'41.578' LS dan 113'53.909' BT, sedangkan stasiun 2 terletak 7'41.500' LS dan 113'53.737' BT, dan stasiun 3 terletak pada 7'41.444' LS dan 113'53.595' BT. Stasiun pengamatan merupakan kawasan Karamba Jaring Apung dimana terdapat 40 unit KJA yang beroperasi. Jarak antara stasiun 1 dan 2 adalah 1,3 $\mathrm{km}$ dan merupakan kawasan yang padat dengan jumlah KJA yang terdapat diantara kurang lebih 17 buah KJA, sedangkan jarak antara stasiun 2 dan 3 adalah $0,93 \mathrm{~km}$ dengan jumlah $\mathrm{KJA}$ yang terdapat diantaranya kurang lebih 11 buah KJA.

Pada saat jumlah KJA melampaui batas tertentu dapat mengakibatkan proses sedimentasi yang tinggi berupa penumpukan sisa pakan di dasar perairan, limbah tersebut akan menyebabkan penurunan kualitas perairan (pengurangan pasokan oksigen dan pencemaran air KJA) yang pada akhirnya mempengaruhi hewan yang dipelihara. Sisa pakan dan metabolisme dari aktifitas pemeliharaan ikan dalam KJA serta limbah domestik yang berasal dari kegiatan pertanian maupun dari limbah rumah tangga menjadi penyebab utama menurunnya fungsi ekosistem perairan yang berakhir pada terjadinya pencemaran perairan, mulai dari eutrofikasi yang menyebabkan ledakan (blooming) fitoplankton dan gulma air, upwelling dan lain-lain yang yang dapat mengakibatkan organisme perairan (terutama ikanikan budidaya) serta diakhiri dengan makin menebalnya lapisan anaerobik di badan air perairan.

Faktor-faktor penting kualitas air lain yang perlu mendapat perhatian diantaranya adalah suhu air, salinitas, oksigen terlarut, alkalinitas, nitrit, nitrat, dan phosphat. Faktor-faktor tersebut dalam suatu tempat terus mengalami perubahan dinamis karena adanya faktor diluar dan didalam sistem yang kemudian saling mempengaruhi antar faktor tersebut. Perubahan lingkungan secara kimia dan fisika yang terjadi secara alamiah dan akibat ulah manusia yang terjadi di lingkungan perairan. Metabolik ikan akan berkurang atau berhenti ketika suhu tidak optimum atau perubahannya terlalu ekstrim. Jika suhu air meningkat maka jumlah kandungan oksigen menurun dan semakin parah ketika konsumsi oksigen oleh ikan dan organisme di dalam air meningkat. Oksigen yang berkurang berdampak pada aktivitas ikan berkurang atau berhenti karena nafsu makannya berhenti. Makanan akan tersisa dan berdampak pada meningkatnya akumulasi ammoniak di air. Suhu juga berpengaruh terhadap munculnya serangan penyakit dan jumlah ikan yang terkena penyakit.

Salinitas air laut di kawasan KJA yang terukur selama penelitian rata-rata adalah 35 ppt. Berdasarkan standart baku mutu air lautKepMen LH No. 51 Tahun 2004 bahwa salinitas untuk biota laut adalah 33 - 34 ppt, sedangkan menurut Sutika (1989) bahwa salinitas air laut pada umumnya berkisar $33-37$ ppt dan berubah-ubah berdasarkan waktu dan ruang. Tingginya nilai salinitas disebabkan karena pengambilan sampel air laut di kawasan KJA tersebut dilakukan selama musim kemarau, Seperti yang dikemukakan oleh Nontji (1987) bahwa sebaran salinitas dipengaruhi oleh berbagai faktor seperti pola sirkulasi air, penguapan, curah hujan dan aliran sungai. 
Kepekatan oksigen terlarut (DO) dipengaruhi oleh beberapa faktor yaitu suhu, kehadiran tanaman fotosintetik, tingkat penetrasi cahaya yang tegantung pada kedalaman dan kekeruhan air, tingkat kederasan aliran air dan jumlah bahan organik yang diuraikan dalam air (Sastrawijaya, 2000). Hal tersebut dapat dilihat pada hasil pengamatan pada stasiun 2 yaitu bahwa saat suhu air di permukaan tinggi $\left(30,3{ }^{\circ} \mathrm{C}\right)$, kandungan oksigen terlarut rendah $(4,37 \mathrm{mg} / \mathrm{l})$ dan tingkat kelarutan bahan organik juga rendah $(103,016 \mathrm{mg} / \mathrm{l})$

. Rendahnya kadar oksigen dapat berpengaruh terhadap fungsi biologis dan lambatnya pertumbuhan, bahkan dapat mengakibatkan kematian. Fungsi oksigen selain untuk pernapasan organisme juga untuk mengoksidasi bahan organik yang ada di dasar sedimen perairan.

Kandungan nitrit yang terukur pada stasiun 1,2 dan 3 sama yaitu $0,001 \mathrm{mg} / \mathrm{L}$, dimana hal tersebut masih berada pada standart baku mutu air laut KepMen LH No. 51 Tahun 2004 yaitu 0.001 mg/L. Sedangkan kandungan nitrat pada KJA dikawasan perairan pantai pasir putih Situbondo rata-rata $5,5 \mathrm{mg} / \mathrm{l}$ di stasiun $1,5,7 \mathrm{mg} / \mathrm{l}$ di stasiun 2 dan $9,3 \mathrm{mg} / 1$ di stasiun 3. Kadar nitra ini termasuk dalam kategori tinggi, hal ini berdasarkan pada baku mutu KepMen LH No. 51 Tahun 2004 dimana kadar nitrat adalah berkisar antara $0.9-3.2 \mathrm{mg} / \mathrm{l}$. Hal ini tentunya harus mendapatkan perhatian karena kadar nitrat yang lebih dari $0.2 \mathrm{mg} / \mathrm{l}$ dapat menyebabkan terjadinya eutrofikasi perairan, dan selanjutnya dapat menyebabkan blooming sekaligus merupakan faktor pemicu bagi pesatnya pertumbuhan tumbuhan air. Kadar nitrat yang lebih dari $5 \mathrm{mg} / \mathrm{L}$ menggambarkan telah terjadinya pencemaran dan perairan pantai pasir putih situbondo yang diakibatkan oleh penumpukan sisa pakan dan feses ikan.

Sebaran kepadatan total bakteri pada perairan budidaya karamba jaring apung dikawasan Pantai Pasir Putih Situbondo menunjukkan pada kisaran sekitar 150.000 - 460.000 koloni/ml. Adanya kepadatan bakteri koliform dan E.coli yang tinggi adalah akibat dari kegiatan budidaya yang menyebabkan penumpukan pakan dan pembuangan limbah dari hatcery sekitar Pantai Pantai Pasir Putih Situbondo. Bakteri tersebut dapat menyebabkan terhambatnya pertumbuhan biota yang di budidayakan atau bahkan menyebabkan penyakit pada manusia yang mengkonsumsi biota yang dibudidayakan (Girard et al., 2005). Perairan Keramba Jaring Apung ini termasuk dalam kategori subur (tidak mengalami pencemaran) sebab dari hasil pengamatan ini didapatkan fitopalnkton yang didominasi oleh kelas Bacillariphyceae atau Diatom yang merupakan indikator bahwa perairan tersebut termasuk subur. Namun dari kelas ini hanya didapatkan dalam presentase yang relatif kecil sehingga tidak terlalu berpengaruh terhadap ekosistem perairan Keramba Jaring Apung. Menurut Nybakken (1992) dalam Erlina (2006) disebutkan bahwa plankton estuaria miskin dalam jumlah spesies. Diatom seringkali mendominasi fitoplankton. Genera diatom yang dominan termasuk Skeletonema, Asterionella, Chaetoceros, Nitzschia, Thalassionema, dan Melosira.

\section{KESIMPULAN DAN SARAN Kesimpulan}

Berdasarkan hasil penelitian yang telah dilakukan di kawasan Karamba Jaring Apung Pantai Pasir Putih Situbondo, dapat disimpulkan bahwa :

1. Kualitas air di lingkungan perairan di kawasan KJA Pantai Pasir Putih Situbondo masih sesuai dengan baku mutu air laut KepMen LH No. 51 Tahun 2004.

2. Kawasan KJA Pantai Pasir Putih Situbondo dinilai layak bagi pengembangan kegiatan budidaya perikanan di Karamba Jaring Apung.

Saran

Penilaian daya dukung lingkungan perairan tidak hanya terbatas pada pengukuran kualitas air dan survey oseanografi, namun juga diperlukan data mengenai kapasitas ketersediaan oksigen terlarut dalam perairan. Sehingga dalam hal ini disarankan untuk melakukan pengukuran kapasitas $\mathrm{O}_{2}$ terlarut pada penelitian selanjutnya.

\section{DAFTAR PUSTAKA}

[1] Affan, J, M. 2012. Identifikasi lokasi untuk pengembangan budidaya karamba jaring apung (KJA) berdasarkan faktor lingkungan dan kualitas air di perairan pantai timur Bangka tengah. Jurnal Depik 1 (1) : 78-85 April 2012.

[2] BPWC (Badan Pengelolaan Waduk Cirata). 2005. Waduk Cirata dan Permasalahannya. Workshop Culture, Cepture Cinflicts : Sustaining Fish production and Livehoods in Indonesia Reservoirs, 1-20 Oktober 2005. Bandung.

[3] Connel, D,W ang Miller, J,G. 1995. Kimia dan Ekotoksikologi Pencemaran. Penerbit Universitas Indonesia. Jakarta.

[4] Effendi, H. 2003. Telaah Kualitas Air. Kanasius. Yogyakarta. 
Ida Adha Anrosana P, Ariesia Ayuning Gemaputri. Kajian Daya Dukung (Carrying Capacity) Lingkungan Perairan Pantai Pasir Putih Situbondo bagi Pengembangan Usaha Karamba Jaring Apung.

[5] Keputusan Menteri Negara Lingkungan Hidup Nomor : 51 Tahun 2004 Tentang Pedoman Penentuan Status Mutu Air. (http://www.menlh.go.id). tanggal akses 3 Oktober 2015.

[6] Lesmana, D. 2001. Kualitas Air Untuk Ikan Hias Air Tawar. Penebar Swadaya. Jakarta.

[7] Odum, E. P. 1986. Fundamental Of Ecology 3rd ed. (Dasar-dasar Ekologi ed. III, alih bahasa Tjahjono Samingan). Gadjag Mada University Press. Yogyakarta.

[8] Peraturan Pemerintah Nomor 82 Tahun 2001 tentang Pengelolaan Kualitas Air dan Pengendalian Pencemaran Air.

[9] Sastrawijaya, A.T., 2000. Pencemaran Lingkungan. Penerbit PT. Rineka Cipta. Jakarta. 247 hal. 